PRINT ISSN 1119-8362

Electronic ISSN 1119-8362
Full-text Available Online at https://www.ajol.info/index.php/jasem

http://ww.bioline.org.br/ja
J. Appl. Sci. Environ. Manage.

Vol. 25 (5) 815-818 May 2021

\title{
Effect of Seed Size and Different Pretreatment Methods on Germination of Albizia zygia (DC.) J. F. Macbr
}

\section{*IROKO, OA; RUFAI, SO; WAHAB, WT}

\author{
Forestry Research Institute of Nigeria, Ibadan, Nigeria \\ *Corresponding Author Email: olayinkairoko@gmail.com; Tel: +2348033187525
}

\begin{abstract}
Albizia zygia produces valuable timber which has received some level of prominence in the international market. However, the seeds are dormant, and the tree species remain undomesticated. This study was conducted to evaluate the effect of seed size and presowing on the germination of Albizia zygia in a nursery. Seeds were grouped into four categories in regard to their length, small $(\leq 0.5 \mathrm{~cm})$, medium $(>0.5<0.8 \mathrm{~cm})$, large $(\geq 0.8 \mathrm{~cm})$, and mixture of small, medium, and large seeds. The seeds were subjected to five main seed pretreatment methods, namely, soaking in sulphuric acid $\left(\mathrm{H}_{2} \mathrm{SO}_{4}\right)$ for 2 minutes, mechanical scarification, soaking in hot water for 5 minutes, soaking in cold water for 24 hours, and control where seeds were sown without any treatment. The results indicate that combination of mechanical scarification and large seeds produced the highest $(100 \%)$ germination. Hot water treatment was effective in large seeds producing $69.0 \%$ germination. The increased germination for mechanically scarified seeds suggests that seed dormancy in Albizia zygia is mainly due to its hard seed coat. Therefore, it is recommended to farmers to adopt use of mechanical scarification and large seeds, since it is safe and effective.
\end{abstract}

\section{DOI: https://dx.doi.org/10.4314/jasem.v25i5.19}

Copyright: Copyright $@ 2021$ Iroko et al. This is an open access article distributed under the Creative Commons Attribution License (CCL), which permits unrestricted use, distribution, and reproduction in any medium, provided the original work is properly cited.

Dates: Received: 20 March 2021; Revised: 27 April 2021; Accepted: 07 May 2021

Keywords: Albizia zygia, pretreatment, seed size, germination percentage and seed

Albizia zygia belongs to the subfamily of Mimosoideae in the family of Fabaceae. It is a deciduous tree that can attained $9-30 \mathrm{~cm}$ height with a spreading crown and a graceful architectural form. Its bole is tall and clear having a diameter of about 24 $\mathrm{cm}$, the bark is grey and smooth. It is Native to Cameroon, Democratic republic of Congo, Gabon, Ghana, Kenya, Nigeria, Sudan, Tanzania and Uganda (Orwa, et al., 2009).Though Albizia zygia is considered a lesser used species. (Apetorgbor, 2007) or medium wood grade species on the basis of their quality (Ogunwusi, 2012), it produces valuable timber (Zabala, 1997) which has received some level of prominence in the international market (Apetorgbor, 2007).

The use of the species in the reclamation of degraded cocoa farm land has been proven to be successful. (Ziblim, et al., 2012). Briquette produced from Albizia zygia sawdust was reported to have high calorific value (Aina, et al., 2009), the fodder are reported to be palatable for animal feeds (Tabuti and Lye 2009), while the leaves are used in preparing soup by the people of cross river state in Nigeria (Orwa et al, 2009). In local medicine different parts of this species is used for the treatments and remedy of diverse ailments and diseases. The bark sap is instilled in the eyes to treat ophthalmia, a bark decoction is administered to treat bronchial diseases, fever, (including malaria) and female sterility, and as a purgative, stomachic, antidote, vermifuge and aphrodisiac (Orwa et al., 2009).

The gum produced from the trunk is used as a binding agent in pharmaceutical industry, reported to produce tablets with better mechanical properties and longer disintegration and dissolution times than those containing gelatin BP. (Kwabena, et al., 2009). Despite the versatility of the species, little effort has been made towards its domestication, probably because of the general assumption that tropical tree species has long gestation period and dearth of information on its growth requirements.

With high demand and pressure on this important multipurpose tree species, if not domesticated and made available to farmers, the generation yet to come may be deprived of the benefits of this important tree species. This called for research on the growth requirements of Albizia zygia. Availability of healthy and vigorous seedlings is one of the important stages towards domestication/plantation establishment of tree species. This research was therefore conducted to 
assess the effects of different seed pretreatment methods and seed size on germination of Albizia zygia.

\section{MATERIALS AND METHODS}

Study Site: The study was carried out in Silviculture Nursery, Department of Sustainable Forest management, Forestry Research Institute of Nigeria, Jericho Hill, Ibadan, Nigeria (FRIN). FRIN is located within longitude $07^{0} 23^{\prime} 18^{\prime \prime} \mathrm{N}$ to $07^{0} 23^{\prime} 43^{\prime \prime} \mathrm{N}$ and latitude $03^{0} 51^{\prime} 20^{\prime \prime} \mathrm{E}$ to $03^{0} 51^{\prime} 43^{\prime \prime} \mathrm{E}$. Mean annual rainfall is about $1548.9 \mathrm{~mm}$, falling within approximately 90 days. The mean maximum temperature is $31.9^{\circ} \mathrm{C}$, minimum $24.2^{\circ} \mathrm{C}$ while the mean daily relative humidity is about $71.9 \%$. Ibadan is the capital of Oyo state, Nigeria. It is in the sub humid agro ecological zone of Nigeria. There are two distinct climatic season which are the dry season (from November to March) and rainy season (April to October). Ibadan is characterized by two peak of rainfall.

Experimental Design: A total of 800 seeds were directly sown in polythene pots, and were subjected to twenty treatments which were completely randomized in four replicates. Each treatment had 10 seeds i.e (20 X 4 X 10). The treatment combination consisted of two factors, namely, seed size and pretreatment methods. The first factor of seed size consisted of seeds of length less than $0.5 \mathrm{~cm}$ and was denoted as small; $0.51 \mathrm{~cm}$ to $0.8 \mathrm{~cm}$ seeds were considered medium; seeds of 0.8 $\mathrm{cm}$ long and greater were categorized large.

A fourth seed size category was a control which consisted of three dimensions (small, large, and medium) of seeds. The second factor of pretreatment methods involved five seed pretreatment methods, namely, cold water soaking for 24 hours, hot water soaking for 5 minutes, and 2 minute immersion in concentrated sulphuric acid $\left(0.3 \mathrm{M} \mathrm{H}_{2} \mathrm{SO}_{4}\right)$, including mechanical scarification by mechanical scarification, and a fifth treatment was a control which consisted of seeds that were left intact.

\section{Pretreatment Procedure}

Cold and Hot Water Treatment: Twenty seeds from each seed size category (small, medium, large, and mixture) were put in similar beaker sizes where cold water at room temperature was poured and the seeds were soaked for 24 hours. Water was then removed and the seeds were planted on the same day. For the hot water treatment, water was heated to approximately $100^{\circ} \mathrm{C}$ and was then poured into beakers containing twenty seeds from each seed category (small, medium, large, and mixture) and was left to stand for 5 minutes after which the seeds were sown.
Immersion in Concentrated Sulphuric Acid: Seeds of small, medium, large, and mixture seed categories were put into separate beakers. Concentrated sulphuric acid $\left(0.3 \mathrm{M} \mathrm{H}_{2} \mathrm{SO}_{4}\right)$ was then added to the beakers each containing twenty seeds and were left to soak for 2 minutes. After immersion, the solution was drained off, and seeds were repeatedly rinsed in running tap water until considered safe to handle. Then the seeds were sown.

Mechanical scarification: Twenty seeds from each size category were mechanically scarified on one side away from the micropyle using metal file and then sown immediately. Watering was done accordingly to keep the beds with adequate moisture. In total, there were twenty treatment combinations and were denoted as follows:

T1: small seeds immersed in $0.3 \mathrm{M}$ sulphuric acid $\left(\mathrm{H}_{2} \mathrm{SO}_{4}\right)$ for 2 minutes;

T2: small seeds with mechanical scarification;

T3: small seeds soaked in hot water at $100^{\circ} \mathrm{C}$ for 5 minutes;

T4: small seeds soaked in cold water at room temperature for 24 hours;

T5: small seeds sown without pretreatment;

T6: large seeds immersed in $0.3 \mathrm{M}$ sulphuric acid $\left(\mathrm{H}_{2} \mathrm{SO}_{4}\right)$ for 2 minutes;

T7: large seeds with mechanical scarification;

T8: large seeds soaked in hot water at $100^{\circ} \mathrm{C}$ for 5 minutes;

T9: large seeds soaked in cold water at room temperature for 24 hours;

T10: large seeds sown without pretreatment;

T11: medium seeds immersed in $0.3 \mathrm{M}$ sulphuric acid $\left(\mathrm{H}_{2} \mathrm{SO}_{4}\right)$ for 2 minutes;

T12: medium seeds with mechanical scarification;

T13: medium seeds soaked in hot water at $100^{\circ} \mathrm{C}$ for 5 minutes;

T14: medium seeds soaked in cold water at room temperature for 24 hours;

T15: medium seeds sown without pretreatment;

T16: mixture of seeds immersed in $0.3 \mathrm{M}$ sulphuric acid $\left(\mathrm{H}_{2} \mathrm{SO}_{4}\right)$ for 2 minutes;

T17: mixture of seeds with mechanical scarification;

T18: mixture of seeds soaked in hot water at $100^{\circ} \mathrm{C}$ for 5 minutes;

T19: mixture of seeds soaked in cold water at room temperature for 24 hours;

T20: mixture of seeds sown without pretreatment.

Data Collection and Analysis: Data on germination were recorded on daily basis for a period of eight weeks (56 days) from the day of sowing. Germination was defined as the emergence of radicle from the seed coat. Daily germination percentages were summed up to obtain cumulative germination for each treatment. 
Data obtained was subjected to Analysis of Variance (ANOVA). Differences between treatment means were separated using Fischer's least significant difference (LSD) at the 0.05 level. The data was analyzed using the following model:

$Y i j k=\mu+S i+P j+(S P)+e i j k \ldots \ldots$ (I)

Where; Yijk is the response variable (germination percentage) of $j$ th observation in $i$ th treatments;

$\mu$ is the overall mean; $S i$ is the fixed effect of seed size $(i=1,2,3,4)$,

$P j$ is the fixed effect of pretreatment methods $(j=1$, $2,3,4,5) ;(S P)$ is the effect of the interaction between seed size and pretreatment methods, and

$e i j k$ is the random residual effect, $e i j k \sim(0, \sigma e 2)$

\section{RESULTS AND DISCUSSION}

There were no significant $(P>0.05)$ differences in germination between seed sizes, although larger seeds had a higher germination $(49.7 \%)$ percentage followed by medium sized seeds $(47.4 \%)$ and then mixture of seeds $(46.7 \%)$. Small seeds had an average of $43.1 \%$ germination. However, there were significant $(P<$ $0.001)$ differences in germination among presowing treatments where mechanical scarification gave the highest germination $(84.4 \%)$ followed by immersion in hot water $(52.5 \%)$ and then immersion in $0.3 \mathrm{M}$ $\mathrm{H}_{2} \mathrm{SO}_{4}$ acid with $43.8 \%$ germination. The result also revealed mechanical scarification had the highest performance in all treatments while the combination of large seeds scarified mechanical had the best performance $(100 \%)$ germination followed by hot water treatment and the large seeds soaked in water had a germination percentage of $69 \%$ while the least performance was observed in seeds with no treatment (control) with a performance of $22.8 \%$ (Figure 1).

Table 1: Mean Germination percentage (\%) for different pretreatment

\begin{tabular}{lllllll}
\hline Seed size & $\mathrm{H}_{2} \mathrm{SO}_{4}$ & $\begin{array}{l}\text { Mechanical } \\
\text { Scarification }\end{array}$ & $\begin{array}{l}\text { Hot } \\
\text { Water }\end{array}$ & $\begin{array}{l}\text { Cold } \\
\text { water }\end{array}$ & Control & Mean \\
\hline Large & 32.0 & 100 & 69.0 & 23.5 & 24.1 & $\mathbf{4 9 . 7}^{\text {a }}$ \\
Medium & 53.0 & 85.0 & 45.0 & 31.2 & 22.8 & $\mathbf{4 7 . 4}^{\mathbf{a}}$ \\
Small & 50.3 & 77.1 & 52.5 & 12.5 & 23.0 & $\mathbf{4 3 . 1}^{\mathbf{a}}$ \\
Mixture & 39.8 & 75.5 & 43.5 & 39.5 & 35.3 & $\mathbf{4 6 . 7}^{\mathbf{a}}$ \\
\hline Mean & $\mathbf{4 3 . 8}^{\text {bc }}$ & $\mathbf{8 4 . 4}^{\mathbf{a}}$ & $\mathbf{5 2 . 5}^{\mathbf{b}}$ & $\mathbf{2 6 . 7}^{\mathbf{c}}$ & $\mathbf{2 6 . 3}^{\mathbf{c}}$ & \\
\hline
\end{tabular}

Note. Means with different superscripts within a row differ $(P<0.001)$

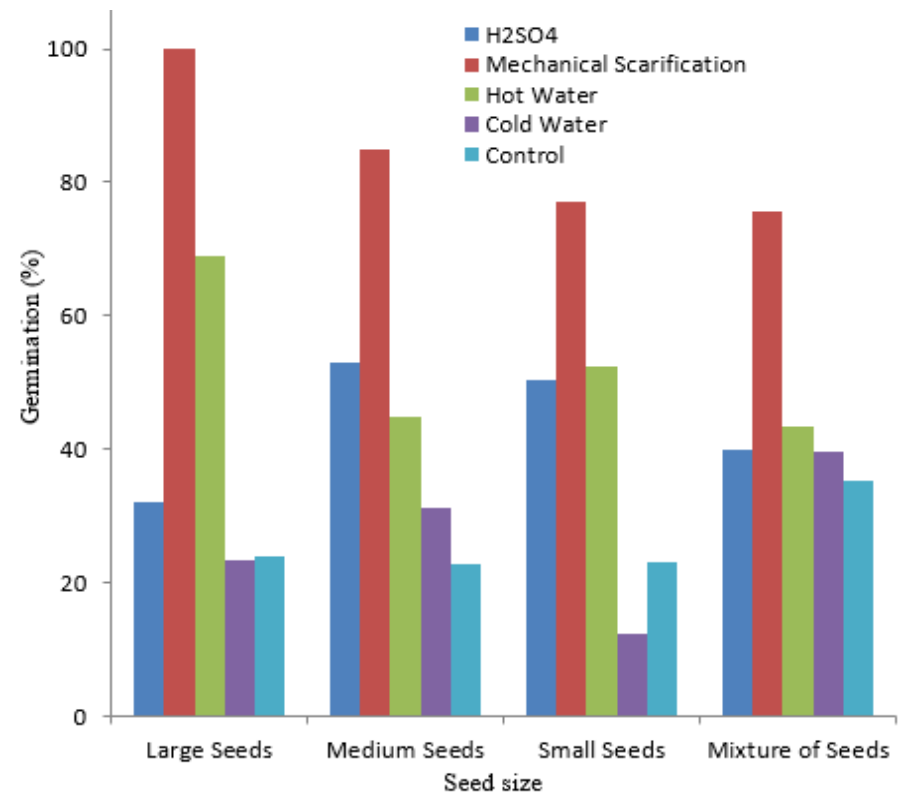

Fig 1: Germination percentage (\%) for different pretreatment

Conclusion: Seed pretreatment methods and seed size affected the germination of Albizia zygia. The larger seeds resulted in higher germination percentage since larger seeds contain more food reserves to support germination. Therefore, this study recommends to farmers to adopt use of mechanical scarification and large seeds, since it is safe and effective. 


\section{REFERENCES}

Aina OM., Adetogun, AC and Iyiola, KA (2009). Heat Energy from Value-added Sawdust Briquettes of Albizia zygia. Ethiopian J. Environ. Stud. Manage. 2(1):42-49

Apetorgber, MM. (2007). Albizia zygia (DC) J.F.Macbr.in: Louppe, D., Oteng-Amoaka, A.A. and Brink, M. (Editors). Prota 7(1): Timber/Bois d'ouvre 1. (CD - ROM).PROTA.Wageningen, Netherlands

Kwabena, O., Emily NNA and Samuel Lugrie K (2009).Preparation and In-vitro Characteristics of Tablet Cores Coated with Albizia, Albizia/khaya and Albizia/hpmc Films. Interactional J. Appl. Pharmaceutics 1 (1)

Ogunwusi, AA (2012). Wood properties of Albizia zygia and Anogeissus leiocarpu: Medium Wood Species Found in Timber Markets in Nigeria. $J$. Bio. Agric. Healthcare. 2(11):123 - 130

Orwa, C. A., Mutua, K. R., Jamnadass, R. and Anthony, S. (2009): Agroforestry Data-base: a tree reference and selection guide version
Tabuti, JRS and Lye, KL (2009). Fodder plants for cattle in kaliro district, Uganda Africa study monographs, 30(3): $161-170$

Zabala, N. 1997.International Workshop on Albizia and Paraserianthes Spp. Proceedings of a workshop held November 13-19, 1994, in Bislig, Surigao del Sur, Philippines. Forest, Farm, and Community Tree Research Reports (Special Issue). Winrock International, Morrilton, Arkansas, USA.

Ziblim, AI, Damian, Tom-Dery and Kingsley, AK (2012). Assessment of Soil Quality Improvement under Teak and Albizia. J. Soil Sci. Environ. Manage. 3(4):91 - 96. 